Journal of Pathology Research Reviews \& Reports

\title{
Showcase to Illustrate How the Web-Server Idna6ma-Pseknc is Working
}

\author{
Kuo-Chen Chou
}

Gordon Life Science Institute, Boston, Massachusetts 02478, United States of America

Corresponding author: Kuo-Chen Chou, Gordon Life Science Institute, Boston, Massachusetts 02478, United States of America; kcchou@gordonlifescience.org or kcchou38@gmail.com

Received: December 03, 2019, Accepted: December 11, 2019, Published: December 15, 2019

Keywords: Web-Server, Idna6ma-Pseknc, N6-methyladenosine, RNA

In 2017 a very powerful web-server predictor has been established for identifying N6-methyladenosine (m6A), which is one of the most important modifications in RNA [1]. To see how the web-server is working, please do the following.

Click the link at http://lin-group.cn/server/iDNA$6 \mathrm{~mA}-\mathrm{PseKNC}$ and you'll see the web-server's top-page as shown in Figure.1

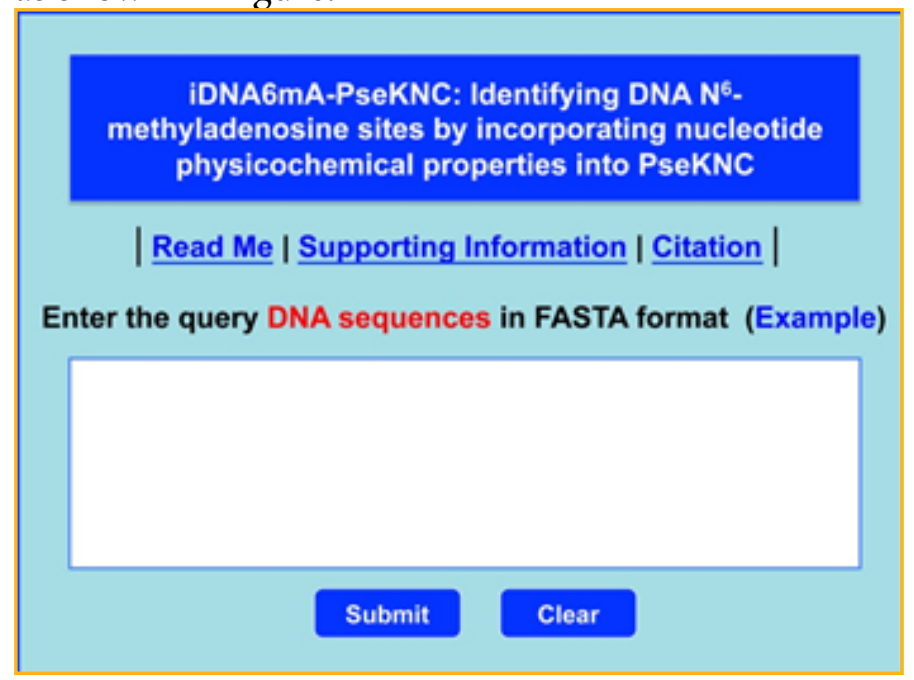

Figure 1. A semi-screenshot for the top-page of the iDNA6mA-PseKNC web-server at http://lin-group.cn/server/iDNA6mA-PseKNC (Adapted from [1] with permission).
Either type or copy/paste the sequences of query DNA sequences into the input box at the center of Fig.1. The input sequence should be in the FASTA format. For the examples of sequences in FASTA format, click the Example button right above the input box.

Click on the Submit button to see the predicted result. For instance, if you use the two DNA sequences in the Example window as the input, after a few seconds, you will see the following on the screen of your computer. (i) Seq 1 contains $17 \mathrm{~A}$ (adenine) nucleotides, and only the ones in the positions $35,41,62$, and 71 may be of $6 \mathrm{~mA}$ modification. (ii) Seq 2 contains 14 A nucleotides, and only the ones in the positions 38,62 , and 71 may be of $6 \mathrm{~mA}$ modification.

Click the Supporting Information button to download the Supporting Information's mentioned in this paper. Click on the Citation button to find the papers that have played the key roles in developing the current predictor of iDNA6mA-PseKNC. It is instructive to point out that the web-server predictor has been developed by strictly observing the guidelines of "Chou's 5-steps rule" and hence have the following notable merits (see, e.g., [229] nd three comprehensive review papers [30-32]): (1) crystal clear in logic development, (2) completely 
transparent in operation, (3) easily to repeat the reported results by other investigators, (4) with high potential in stimulating other sequence-analyzing methods, and (5) very convenient to be used by the majority of experimental scientists.

Moreover, it has not escaped our notice that during the development of iDNA6mA-PseKNC web-server, the approach of general pseudo amino acid components [33] or PseAAC [34] had been utilized and hence its accuracy would be much higher than its counterparts, as concurred by many investigators $[2-6,8-11,13,18$, 26, 30, 32-301].

It is anticipated that iDNA6mA-PseKNC may become a very useful high throughput tool for conducting genome analysis as well as drug development.

For the remarkable and awesome roles of the "5-steps rule" in driving proteome, genome analyses and drug development, see a series of recent papers [31, 32, 292, 302-310]. Where the rule and its wide applications have been very impressively presented from various aspects or at different angles.

\section{References}

1. W Chen, P Feng, H Yang, H Ding, $\mathrm{H}$ Lin, KC Chou (2017) iRNA-AI: identifying the adenosine to inosine editing sites in RNA sequences. Oncotarget 8: 42084217.

2. O Barukab, YD Khan, SA Khan, KC Chou (2019) iSulfoTyr-PseAAC: Identify tyrosine sulfation sites by incorporating statistical moments via Chou's 5-steps rule and pseudo components Current Genomics https:/ doi.org/10.2174/1389202920666190819091609.

3. X Cheng, WZ Lin, X Xiao, KC Chou (2019) pLoc_ bal-mAnimal: predict subcellular localization of animal proteins by balancing training dataset and PseAAC. Bioinformatics 35: 398-406.

4. KC Chou, X Cheng, X Xiao (2019) pLoc_bal-mHum: predict subcellular localization of human proteins by PseAAC and quasi-balancing training dataset Genomics 111: 1274-1282.

5. KC Chou, X Cheng, X Xiao (2019) pLoc_bal-mEuk: predict subcellular localization of eukaryotic proteins by general PseAAC and quasi-balancing training dataset. Med Chem 15: 472-485.

6. A Ehsan, MK Mahmood, YD Khan, OM Barukab, SA
Khan, KC Chou (2019) iHyd-PseAAC (EPSV): Identify hydroxylation sites in proteins by extracting enhanced position and sequence variant feature via Chou's 5-step rule and general pseudo amino acid composition. Current Genomics 20: 124-133.

7. $\mathrm{P}$ Feng, $\mathrm{H}$ Yang, $\mathrm{H}$ Ding, $\mathrm{H}$ Lin, $\mathrm{W}$ Chen, KC Chou (2019) iDNA6mA-PseKNC: Identifying DNA N(6)methyladenosine sites by incorporating nucleotide physicochemical properties into PseKNC. Genomics 111: 96-102.

8. W Hussain, SD Khan, N Rasool, SA Khan, KC Chou (2019) SPalmitoylC-PseAAC: A sequence-based model developed via Chou's 5-steps rule and general PseAAC for identifying S-palmitoylation sites in proteins. Anal Biochem 568: 14-23.

9. W Hussain, YD Khan, N Rasool, SA Khan, KC Chou (2019) SPrenylC-PseAAC: A sequence-based model developed via Chou's 5-steps rule and general PseAAC for identifying S-prenylation sites in proteins. J Theor Biol 468: 1-11.

10. S Ilyas, W Hussain, A Ashraf, YD Khan, SA Khan, KC Chou (2019) iMethylK-PseAAC: Improving accuracy for lysine methylation sites identification by incorporating statistical moments and position relative features into general PseAAC via Chou's 5-steps rule. Current Genomics doi: 10.2174/1389202920666190809 095206 (2019).

11. J Jia, X Li, W Qiu, X Xiao, KC Chou (2019) iPPIPseAAC(CGR): Identify protein-protein interactions by incorporating chaos game representation into PseAAC. Journal of Theoretical Biology 460: 195-203.

12. YD Khan, A Batool, N Rasool, A Khan, KC Chou (2019) Prediction of nitrosocysteine sites using position and composition variant features. Letters in Organic Chemistry 16: 283-293.

13. YD Khan, M Jamil, W Hussain, N Rasool, SA Khan, KC Chou (2019) pSSbond-PseAAC: Prediction of disulfide bonding sites by integration of PseAAC and statistical moments. J Theor Biol 463: 47-55.

14. Y Lu, S Wang, J Wang, G Zhou, Q Zhang, X Zhou, B Niu, Q Chen, KC Chou (2019) An Epidemic Avian Influenza Prediction Model Based on Google Trends. Letters in Organic Chemistry 16: 303-310. 
15. B Niu, C Liang, Y Lu, M Zhao, Q Chen, Y Zhang, L Zheng, KC Chou (2019) Glioma stages prediction based on machine learning algorithm combined with protein-protein interaction networks. Genomics doi: 10.1016/j.ygeno.2019.05.024Get (2019).

16. G Pugalenthi, V Nithya, KC Chou, G Archunan (2019) Nglyc: A random forest method for prediction of N-Glycosylation sites in eukaryotic protein sequence. Protein \& Peptide Letters doi: 10.2174/092986652666 6191002111404 (2019).

17. Salman, M Khan, N Iqbal, T Hussain, S Afzal, KC Chou (2019) A two-level computation model based on deep learning algorithm for identification of piRNA and their functions via Chou's 5-steps rule. International Journal of Peptide Research and Therapeutics (IJPRT) htpps:/doi.org/10.1007/s10989-019-09887-3 (2019).

18. X Xiao, X Cheng, G Chen, Q Mao, KC Chou (2019) pLoc bal-mGpos: predict subcellular localization of Gram-positive bacterial proteins by quasi-balancing training dataset and PseAAC. Genomics 111: 886-892. 19. X Xiao, ZC Xu, WR Qiu, P Wang, HT Ge, KC Chou, iPSW(2L)-PseKNC: A two-layer predictor for identifying promoters and their strength by hybrid features via pseudo K-tuple nucleotide composition. Genomics 111: 1785-1793.

20. L Yang, Y Lv, S Wang, Q Zhang, Y Pan, D Su, Q Lu, Y Zuo (2019) Identifying FL11 subtype by characterizing tumor immune microenvironment in prostate adenocarcinoma via Chou's 5-steps rule. Genomics https://doi.org/10.1016/j.ygeno.2019.08.021 (2019).

20. L Yang, Y Lv, S Wang, Q Zhang, Y Pan, D Su, Q Lu, Y Zuo (2019) Identifying FL11 subtype by characterizing tumor immune microenvironment in prostate adenocarcinoma via Chou's 5-steps rule. Genomics https://doi.org/10.1016/j.ygeno.2019.08.021 (2019).

21. A Wiktorowicz, A Wit, A Dziewierz, L Rzeszutko, D Dudek, P Kleczynski (2019) Calcium Pattern Assessment in Patients with Severe Aortic Stenosis Via the Chou's 5-Steps Rule. Current Pharmaceutical Design https:/doi.org/10.2174/1381612825666190930 101258 (2019).

22. S Vishnoi, P Garg, P Arora (2019) Physicochemical n-Grams Tool: A tool for protein physicochemical descriptor generation via Chou's 5-steps rule. Chem Biol Drug Des htpps://doi.org/10.1111/cbdd.13617 or https://www.ncbi.nlm.nih.gov/pubmed/31483930 (2019).

23. Y Liang, S Zhang (2019) Identifying DNase I hypersensitive sites using multi-features fusion and F-score features selection via Chou's 5-steps rule.
Biophys Chem 253: 106227.

24. R Liang, J Xie, C Zhang, M Zhang, H Huang, H Huo, X Cao, B Niu (2019) Identifying Cancer Targets Based on Machine Learning Methods via Chou's 5-steps Rule and General Pseudo Components. Current Topics in Medicnal Chemistry htpps://doi.org/10.2174/156802 6619666191016155543 (2019).

25. J Lan, J Liu, C Liao, DJ Merkler, Q Han, J Li (2019) A Study for Therapeutic Treatment against Parkinson's Disease via Chou's 5-steps Rule. Current Topics in Medicinal Chemistry https://doi.org/10.2174/15680 26619666191019111528 or http://www.eurekaselect. com/175887/article (2019).

26. M Kabir, S Ahmad, M Iqbal, M Hayat (2019) iNR2L: A two-level sequence-based predictor developed via Chou's 5-steps rule and general PseAAC for identifying nuclear receptors and their families. Genomics https:// www.ncbi.nlm.nih.gov/pubmed/30779939 (2019).

27. Z Ju, SY Wang (2019) Prediction of lysine formylation sites using the composition of $\mathrm{k}$-spaced amino acid pairs via Chou's 5-steps rule and general pseudo components. Genomics htpps:/doi.org/10.1016/j.ygeno.2019.05.027 or https://www.ncbi.nlm.nih.gov/pubmed/31175975 (2019).

28. X Du, Y Diao, H Liu, S Li (2019) MsDBP: Exploring DNA-binding Proteins by Integrating Multi-scale Sequence Information via Chou's 5-steps Rule. Journal of Proteome Research 18 (2019) 3119-3132.

29. Y Chen, X Fan (2019) Use of Chou's 5-Steps Rule to Reveal Active Compound and Mechanism of Shuangshen Pingfei San on Idiopathic Pulmonary Fibrosis. Current Molecular Medicine https://doi.org/1 $0.2174 / 1566524019666191011160543$ (2019).

30. KC Chou (2011) Some remarks on protein attribute prediction and pseudo amino acid composition (50th Anniversary Year Review, 5-steps rule). Journal of Theoretical Biology 273: 236-247.

31. KC Chou (2019) Advance in predicting subcellular localization of multi-label proteins and its implication for developing multi-target drugs. Current Medicinal Chemistry 26: 4918-4943.

32. KC Chou (2019) Impacts of pseudo amino acid c mponents and 5-steps rule to proteomics and proteome analysis. Current Topics in Medicinak Chemistry (CTMC) (Special Issue ed. G.P Zhou) https://doi.org/ 10.2174/1568026619666191018100141 or http://www. eurekaselect.com/175823/article (2019).

33. KC Chou (2001) Prediction of protein cellular attributes using pseudo amino acid composition. PROTEINS: Structure, Function, and Genetics 43: 246255.

34. KC Chou (2005) Using amphiphilic pseudo amino 
acid composition to predict enzyme subfamily classes. Bioinformatics 21: 10-19.

35. ZM Guo (2002) Prediction of membrane protein types by using pattern recognition method based on pseudo amino acid composition. Master Thesis, Bio-X Life Science Research Center, Shanghai Jiaotong University (2002).

36. YD Cai, KC Chou (2003) Nearest neighbour algorithm for predicting protein subcellular location by combining functional domain composition and pseudo amino acid composition. Biochem Biophys Res Comm (BBRC) 305: 407-411.

37. KC Chou, YD Cai (2003) Predicting protein quaternary structure by pseudo amino acid composition. PROTEINS: Structure, Function, and Genetics 53: 282289.

38. KC Chou, YD Cai (2003) Prediction and classification of protein subcellular location: sequence-order effect and pseudo amino acid composition. Journal of Cellular Biochemistry 90: 1250-1260.

39. YX Pan, ZZ Zhang, ZM Guo, GY Feng, ZD Huang L He (2003) Application of pseudo amino acid composition for predicting protein subcellular location: stochastic signal processing approach. Journal of Protein Chemistry 22: 395-402.

40. KC Chou, YD Cai (2004) Predicting subcellular localization of proteins by hybridizing functional domain composition and pseudo amino acid composition. Journal of Cellular Biochemistry 91: 1197-1203.

41. M Wang, J Yang, GP Liu, ZJ Xu, KC Chou (2004) Weighted-support vector machines for predicting membrane protein types based on pseudo amino acid composition. Protein Engineering, Design, and Selection 17 (2004) 509-516.

42. YD Cai, KC Chou (2005) Predicting enzyme subclass by functional domain composition and pseudo amino acid composition. Journal of Proteome Research 4: 967-971.

43. YD Cai, GP Zhou, KC Chou (2005) Predicting enzyme family classes by hybridizing gene product composition and pseudo amino acid composition. Journal of Theoretical Biology 234: 145-149.

44. Y Gao, SH Shao, X Xiao, YS Ding, YS Huang, ZD Huang, KC Chou (2005) Using pseudo amino acid composition to predict protein subcellular location: approached with Lyapunov index, Bessel function, and Chebyshev filter. Amino Acids 28: 373-376.

45. H Liu, J Yang, M Wang, L Xue, KC Chou (2005) Using Fourier spectrum analysis and pseudo amino acid composition for prediction of membrane protein types. The Protein Journal 24: 385-389.

46. HB Shen, KC Chou (2005) Using optimized evidence-theoretic K-nearest neighbor classifier and pseudo amino acid composition to predict membrane protein types. Biochemical \& Biophysical Research Communications (BBRC) 334: 288-292.

47. HB Shen, KC Chou (2005) Predicting protein subnuclear location with optimized evidence-theoretic K-nearest classifier and pseudo amino acid composition. Biochem Biophys Res Comm. (BBRC) 337: 752-756.

48. YD Cai, KC Chou (2006) Predicting membrane protein type by functional domain composition and pseudo amino acid composition. Journal of Theoretical Biology 238: 395-400.

49. C Chen, YX Tian, XY Zou, PX Cai, JY Mo (2006) Using pseudo amino acid composition and support vector machine to predict protein structural class. J Theor Biol 243: 444-8.

50.C Chen, X Zhou, Y Tian, X Zou, P Cai (2006) Predicting protein structural class with pseudo amino acid composition and support vector machine fusion network. Analytical Biochemistry 357: 116-21.

51. P Du, Y Li (2006) Prediction of protein submitochondria locations by hybridizing pseudo amino acid composition with various physicochemical features of segmented sequence. BMC Bioinformatics 7: 518.

52. S Mondal, R Bhavna, R Mohan Babu, S Ramakumar (2006) Pseudo amino acid composition and multiclass support vector machines approach for conotoxin superfamily classification. J Theor Biol 243: 252-260.

53. HB Shen, J Yang, KC Chou (2006) Fuzzy KNN for predicting membrane protein types from pseudo amino acid composition. Journal of Theoretical Biology 240: 9-13.

54. SQ Wang, J Yang, KC Chou (2006) Using stacked generalization to predict membrane protein types based on pseudo amino acid composition. Journal of Theoretical Biology 242: 941-946.

55. X Xiao, SH Shao, YS Ding, ZD Huang, KC Chou (2006) Using cellular automata images and pseudo amino acid composition to predict protein subcellular location. Amino Acids 30: 49-54.

56. X Xiao, S H Shao, ZD Huang, KC Chou (2006) Using pseudo amino acid composition to predict protein structural classes: approached with complexity measure factor. Journal of Computational Chemistry 27: 478482.

57. SW Zhang, Q Pan, HC Zhang, ZC Shao, JY Shi (2006) Prediction protein homo-oligomer types by pseudo amino acid composition: Approached with an improved feature extraction and naive Bayes feature fusion. Amino Acids 30: 461-468.

58. GP Zhou, YD Cai (2006) Predicting protease types by hybridizing gene ontology and pseudo amino acid composition. PROTEINS: Structure, Function, 
and Bioinformatics 63: 681-684.

59. YL Chen, QZ Li (2007) Prediction of apoptosis protein subcellular location using improved hybrid approach and pseudo amino acid composition. Journal of Theoretical Biology 248: 377-381.

60. YS Ding, TL Zhang, KC Chou (2007) Prediction of protein structure classes with pseudo amino acid composition and fuzzy support vector machine network. Protein \& Peptide Letters 14: 811-815.

61. H Lin, QZ Li (2007) Predicting conotoxin superfamily and family by using pseudo amino acid composition and modified Mahalanobis discriminant. Biochem Biophys Res Commun 354: 548-51.

62. H Lin, QZ Li (2007) Using Pseudo Amino Acid Composition to Predict Protein Structural Class: Approached by Incorporating 400 Dipeptide Components. Journal of Computational Chemistry 28: 1463-1466.

63. P Mundra, M Kumar, KK Kumar, VK Jayaraman, BD Kulkarni (2007) Using pseudo amino acid composition to predict protein subnuclear localization: Approached with PSSM. Pattern Recognition Letters 28: 1610-1615. 64. JY Shi, SW Zhang, Q Pan, YM Cheng, J Xie (2007) Prediction of protein subcellular localization by support vector machines using multi-scale energy and pseudo amino acid composition. Amino Acids 33: 69-74.

65. TL Zhang, YS Ding (2007) Using pseudo amino acid composition and binary-tree support vector machines to predict protein structural classes. Amino Acids 33: 623-629.

66.XB Zhou, C Chen, ZC Li, XY Zou (2007) Using Chou's amphiphilic pseudo amino acid composition and support vector machine for prediction of enzyme subfamily classes. Journal of Theoretical Biology 248: 546-551.

67. Y Diao, D Ma, Z Wen, J Yin, J Xiang, M Li (2008) Using pseudo amino acid composition to predict transmembrane regions in protein: cellular automata and Lempel-Ziv complexity. Amino Acids 34: 111-117. 68. YS Ding, TL Zhang (2008) Using Chou's pseudo amino acid composition to predict subcellular localization of apoptosis proteins: an approach with immune genetic algorithm-based ensemble classifier. Pattern Recognition Letters 29: 1887-1892.

69. Y Fang, Y Guo, Y Feng, M Li (2008) Predicting DNAbinding proteins: approached from Chou's pseudo amino acid composition and other specific sequence features. Amino Acids 34: 103-109.

70. Q Gu, Y Ding, T Zhang (2008) Prediction of G-protin-coupled receptor classes with pseudo amino acid composition. IEEE Xplore (iCBBE, Shanghai, China) (2008).

71. X Jiang, R Wei, TL Zhang, Q Gu (2008) Using the concept of Chou's pseudo amino acid composition to predict apoptosis proteins subcellular location: an approach by approximate entropy. Protein \& Peptide Letters 15: 392-396.

72. X Jiang, R Wei, Y Zhao, T Zhang (2008) Uusing Chou's pseudo amino acid composition based on approximate entropy and an ensemble of AdaBoost classifiers to predict protein subnuclear location. Amino Acids 34: 669-675.

73. FM Li, QZ Li (2008) Using pseudo amino acid composition to predict protein subnuclear location with improved hybrid approach. Amino Acids 34: 119-125.

74. FM Li, QZ Li (2008) Predicting protein subcellular location using Chou's pseudo amino acid composition and improved hybrid approach. Protein \& Peptide Letters 15: 612-616.

75. H Lin (2008) The modified Mahalanobis discriminant for predicting outer membrane proteins by using Chou's pseudo amino acid composition. Journal of Theoretical Biology 252: 350-356.

76. H Lin, H Ding, FB Feng-Biao Guo, AY Zhang, J Huang (2008) Predicting subcellular localization of mycobacterial proteins by using Chou's pseudo amino acid composition. Protein \& Peptide Letters 15: 739744.

77. L Nanni, A Lumini (2008) Genetic programming for creating Chou's pseudo amino acid based features for submitochondria localization. Amino Acids 34: 653-660.

78. HB Shen, KC Chou (2008) PseAAC: a flexible webserver for generating various kinds of protein pseudo amino acid composition. Analytical Biochemistry 373: 386-388.

79. JY Shi, SW Zhang, Q Pan, GP Zhou (2008) Using Pseudo Amino Acid Composition to Predict Protein Subcellular Location: Approached with Amino Acid Composition Distribution. Amino Acids 35: 321-327.

80. X Xiao, WZ Lin, KC Chou (2008) Using grey dynamic modeling and pseudo amino acid composition to predict protein structural classes. Journal of Computational Chemistry 29: 2018-2024.

81. X Xiao, P Wang, KC Chou (2008) Predicting protein structural classes with pseudo amino acid composition: an approach using geometric moments of cellular automaton image. Journal of Theoretical Biology 254: 691-696.

82. GY Zhang, BS Fang (2008) Predicting the cofactors of oxidoreductases based on amino acid composition distribution and Chou's amphiphilic pseudo amino acid composition. Journal of Theoretical Biology 253: 310315.

83. GY Zhang, HC Li, JQ Gao, BS Fang (2008) Predicting lipase types by improved Chou's pseudo amino acid composition. Protein \& Peptide Letters 15: 1132-1137. 
84. SW Zhang, W Chen, F Yang, Q Pan (2008) Using Chou's pseudo amino acid composition to predict protein quaternary structure: a sequence-segmented PseAAC approach. Amino Acids 35: 591-598.

85. SW Zhang, YL Zhang, HF Yang, CH Zhao, Q Pan (2008) Using the concept of Chou's pseudo amino acid composition to predict protein subcellular localization: an approach by incorporating evolutionary information and von Neumann entropies. Amino Acids 34: 565-572. 86. TL Zhang, YS Ding, KC Chou (2008) Prediction protein structural classes with pseudo amino acid composition: approximate entropy and hydrophobicity pattern. Journal of Theoretical Biology 250: 186-193. 87. C Chen, L Chen, X Zou, P Cai (2009) Prediction of protein secondary structure content by using the concept of Chou's pseudo amino acid composition and support vector machine. Protein \& Peptide Letters 16: 27-31.

88. KC Chou (2009) Pseudo amino acid composition and its applications in bioinformatics, proteomics and system biology. Current Proteomics 6: 262-274.

89. H Ding, L Luo, H Lin (2009) Prediction of cell wall lytic enzymes using Chou's amphiphilic pseudo amino acid composition. Protein \& Peptide Letters 16: 351-355.

90. P Du, S Cao, Y Li (2009) SubChlo: predicting protein subchloroplast locations with pseudo amino acid composition and the evidence-theoretic K-nearest neighbor (ET-KNN) algorithm. Journal of Theoretical Biolology 261: 330-335.

91. QB Gao, ZC Jin, XF Ye, C Wu, J He (2009) Prediction of nuclear receptors with optimal pseudo amino acid composition. Analytical Biochemistry 387 : 54-59.

92. DN Georgiou, TE Karakasidis, JJ Nieto, A Torres (2009) Use of fuzzy clustering technique and matrices to classify amino acids and its impact to Chou's pseudo amino acid composition. Journal of Theoretical Biology 257: 17-26. http://en.wikipedia.org/wiki/ Pseudo amino acid composition, Pseudo amino acid composition, Wikipedia, 2009.

93. ZC Li, XB Zhou, Z Dai, XY Zou (2009) Prediction of protein structural classes by Chou's pseudo amino acid composition: approached using continuous wavelet transform and principal component analysis. Amino Acids 37: 415-425.

94. H Lin, H Wang, H Ding, YL Chen, QZ Li (2009) Prediction of Subcellular Localization of Apoptosis Protein Using Chou's Pseudo Amino Acid Composition. Acta Biotheoretica 57: 321-330.

95. JD Qiu, JH Huang, RP Liang, XQ Lu (2009) Prediction of G-protein-coupled receptor classes based on the concept of Chou's pseudo amino acid composition: an approach from discrete wavelet transform. Analytical Biochemistry 390: 68-73.

96. X Xiao, P Wang, KC Chou (2009) Predicting protein quaternary structural attribute by hybridizing functional domain composition and pseudo amino acid composition. Journal of Applied Crystallography 42: 169-173.

97. YH Zeng, YZ Guo, RQ Xiao, L Yang, LZ Yu, ML Li (2009) Using the augmented Chou's pseudo amino acid composition for predicting protein submitochondria locations based on auto covariance approach. Journal of Theoretical Biology 259: 366-372.

98. M Esmaeili, H Mohabatkar, S Mohsenzadeh (2010) Using the concept of Chou's pseudo amino acid composition for risk type prediction of human papillomaviruses. Journal of Theoretical Biology 263: 203-209.

99. QB Gao, XF Ye, ZC Jin, J He (2010) Improving discrimination of outer membrane proteins by fusing different forms of pseudo amino acid composition. Analytical Biochemistry 398: 52-59.

100. Q Gu, Y Ding, T Zhang, Y Shen (2010) Prediction of G-protein-coupled receptor classes with pseudo amino acid composition]. Journal of biomedical engineering 27: 500-504.

101. Q Gu, YS Ding, TL Zhang (2010) Prediction of G-Protein-Coupled Receptor Classes in Low Homology Using Chou's Pseudo Amino Acid Composition with Approximate Entropy and Hydrophobicity Patterns. Protein \& Peptide Letters 17: 559-567.

102. KK Kandaswamy, G Pugalenthi, S Moller, E Hartmann, KU Kalies, PN Suganthan, T Martinetz (2010) Prediction of Apoptosis Protein Locations with Genetic Algorithms and Support Vector Machines Through a New Mode of Pseudo Amino Acid Composition. Protein and Peptide Letters 17: 14731479.

103. T Liu, X Zheng, C Wang, J Wang (2010) Prediction of Subcellular Location of Apoptosis Proteins using Pseudo Amino Acid Composition: An Approach from Auto Covariance Transformation. Protein \& Peptide Letters 17: 1263-1269.

104. H Mohabatkar (2010) Prediction of cyclin proteins using Chou's pseudo amino acid composition. Protein \& Peptide Letters 17: 1207-1214.

105. L Nanni, S Brahnam, A Lumini (2010) High performance set of PseAAC and sequence based descriptors for protein classification. Journal of Theoretical Biology 266: 1-10.

106. XH Niu, NN Li, F Shi, XH Hu, JB Xia, HJ Xiong (2010) Predicting protein solubility with a hybrid approach by pseudo amino Acid composition. Protein and Peptide Letters 17: 1466-1472.

107. JD Qiu, JH Huang, SP Shi, RP Liang (2010) Using the concept of Chou's pseudo amino acid 
composition to predict enzyme family classes: an approach with support vector machine based on discrete wavelet transform. Protein \& Peptide Letters 17: 715722.

108. SS Sahu, G Panda (2010) A novel feature representation method based on Chou's pseudo amino acid composition for protein structural class prediction. Computational Biology and Chemistry 34: 320-327.

109. YC Wang, XB Wang, ZX Yang, NY Deng (2010) Prediction of enzyme subfamily class via pseudo amino acid composition by incorporating the conjoint triad feature. Protein \& Peptide Letters 17: 1441-1449.

110. J Wu, ML Li, LZ Yu C Wang (2010) An ensemble classifier of support vector machines used to predict protein structural classes by fusing auto covariance and pseudo amino acid composition. Protein J 29: 62-67.

111. L Yu, Y Guo, Y Li, G Li, M Li, J Luo, W Xiong, W Qin (2010) SecretP: Identifying bacterial secreted proteins by fusing new features into Chou's pseudo amino acid composition. Journal of Theoretical Biology 267: 1-6.

112. H Ding, L Liu, FB Guo, J. Huang, H Lin (2011) Identify Golgi protein types with modified mahalanobis discriminant algorithm and pseudo amino acid composition. Protein \& Peptide Letters 18: 58-63.

113. J Guo, N Rao, G Liu, Y Yang, G Wang (2011) Predicting protein folding rates using the concept of Chou's pseudo amino acid composition. Journal of Computational Chemistry 32: 1612-1617.

114. M Hayat, A Khan (2011) Predicting membrane protein types by fusing composite protein sequence features into pseudo amino acid composition. Journal of Theoretical Biology 271: 10-17.

115. L Hu, L Zheng, Z Wang, B Li, L Liu (2011) Using pseudo amino Acid composition to predict protease families by incorporating a series of protein biological features. Protein and Peptide Letters 18: 552-558.

116. Y Huang, L Yang, T Wang (2011) Phylogenetic analysis of DNA sequences based on the generalized pseudo amino acid composition. Journal of Theoretical Biology 269: 217-223.

117. X Jingbo, Z Silan, S Feng, X Huijuan, H Xuehai, N Xiaohui, L Zhi (2011) Using the concept of pseudo amino acid composition to predict resistance gene against Xanthomonas oryzae pv. oryzae in rice: An approach from chaos games representation. Journal of Theoretical Biology 284: 16-23.

118. B Liao, JB Jiang, QG Zeng, W Zhu (2011) Predicting Apoptosis Protein Subcellular Location with PseAAC by Incorporating Tripeptide Composition. Protein \& Peptide Letters 18 (2011) 1086-1092.

119. H Lin, H Ding (2011) Predicting ion channels and their types by the dipeptide mode of pseudo amino acid composition. Journal of Theoretical Biology 269: 64-69.
120. J Lin, Y Wang (2011) Using a novel AdaBoost algorithm and Chou's pseudo amino acid composition for predicting protein subcellular localization. Protein \& Peptide Letters 18: 1219-1225.

121. J. Lin, Y. Wang, X. Xu, A novel ensemble and composite approach for classifying proteins based on Chou's pseudo amino acid composition. African Journal of Biotechnology 10 (2011) 16963-16968.

122. XL Liu, JL Lu, XH Hu (2011) Predicting Thermophilic Proteins with Pseudo Amino Acid Composition: Approached from Chaos Game Representation and Principal Component Analysis. Protein \& Peptide Letters 18: 1244-1250.

123. A Mahdavi, S Jahandideh (2011) Application of density similarities to predict membrane protein types based on pseudo amino acid composition. Journal of Theoretical Biology 276: 132-137.

124. H Mohabatkar, M Mohammad Beigi, A Esmaeili (2011) Prediction of GABA(A) receptor proteins using the concept of Chou's pseudo amino acid composition and support vector machine. Journal of Theoretical Biology 281: 18-23.

125. BM Mohammad, M Behjati, H Mohabatkar (2011) Prediction of metalloproteinase family based on the concept of Chou's pseudo amino acid composition using a machine learning approach. Journal of Structural and Functional Genomics 12: 191-197.

126. JD Qiu, XY Sun, SB Suo, SP Shi, SY Huang, RP Liang, L Zhang (2011) Predicting homo-oligomers and hetero-oligomers by pseudo amino acid composition: an approach from discrete wavelet transformation. Biochimie 93: 1132-1138.

127. JD Qiu, SB Suo, XY Sun, SP Shi, RP Liang (2011) OligoPred: A web-server for predicting homooligomeric proteins by incorporating discrete wavelet transform into Chou's pseudo amino acid composition. Journal of Molecular Graphics \& Modelling 30: 129134.

128. R Shi, C Xu (2011) Prediction of rat protein subcellular localization with pseudo amino Acid composition based on multiple sequential features. Protein and Peptide Letters 18: 625-633.

129. M Shu, X Cheng, Y Zhang, Y Wang, Y Lin, L Wang, Z Lin (2011) Predicting the Activity of ACE Inhibitory Peptides with a Novel Mode of Pseudo Amino Acid Composition. Protein \& Peptide Letters 18: 1233-1243. 130. D Wang, L Yang, Z Fu, J Xia (2011) Prediction of thermophilic protein with pseudo amino Acid composition: an approach from combined feature selection and reduction. Protein \& Peptide Letters 18: 684-689.

131. W Wang, XB Geng, Y Dou, T Liu, X Zheng (2011) Predicting protein subcellular localization by pseudo 
amino Acid composition with a segment-weighted and features-combined approach. Protein and Peptide Letters 18: 480-487.

132. X Xiao, KC Chou (2011) Using pseudo amino acid composition to predict protein attributes via cellular automata and other approaches. Current Bioinformatics 6: $251-260$.

133. X Xiao, P Wang, KC Chou (2011) GPCR-2L: Predicting $G$ protein-coupled receptors and their types by hybridizing two different modes of pseudo amino acid compositions. Molecular Biosystems 7: 911-919.

134. R Zia Ur, A Khan (2011) Prediction of GPCRs with Pseudo Amino Acid Composition: Employing Composite Features and Grey Incidence Degree Based Classification. Protein \& Peptide Letters 18: 872-878.

135. D Zou, Z He, J He, Y Xia (2011) Supersecondary structure prediction using Chou's pseudo amino acid composition. Journal of Computational Chemistry 32: 271-278.

136. JZ Cao, WQ Liu, H Gu (2012) Predicting Viral Protein Subcellular Localization with Chou's Pseudo Amino Acid Composition and Imbalance-Weighted Multi-Label K-Nearest Neighbor Algorithm. Protein and Peptide Letters 19: 1163-1169.

137. C Chen, ZB Shen, XY Zou (2012) Dual-Layer Wavelet SVM for Predicting Protein Structural Class Via the General Form of Chou's Pseudo Amino Acid Composition. Protein \& Peptide Letters 19: 422-429.

138. YL Chen, QZ Li, LQ Zhang (2012) Using increment of diversity to predict mitochondrial proteins of malaria parasite: integrating pseudo amino acid composition and structural alphabet. Amino Acids 42: 1309-16.

139. P Du, X Wang, C Xu, Y Gaom (2012) PseAACBuilder: A cross-platform stand-alone program for generating various special Chou's pseudo amino acid compositions. Analytical Biochemistry 425: 117-119.

140. GL Fan, QZ Li (2012) Predict mycobacterial proteins subcellular locations by incorporating pseudoaverage chemical shift into the general form of Chou's pseudo amino acid composition. Journal of Theoretical Biology 304: 88-95.

141. GL Fan, QZ Lin (2012) Predicting protein submitochondria locations by combining different descriptors into the general form of Chou's pseudo amino acid composition. Amino Acids 43: 545-555.

142. QB Gao, H Zhao, X Ye, J He (2012) Prediction of pattern recognition receptor family using pseudo amino acid composition. Biochemical and Biophysical Research Communications 417: 73-77.

141. GL Fan, QZ Lin (2012) Predicting protein submitochondria locations by combining different descriptors into the general form of Chou's pseudo amino acid composition. Amino Acids 43: 545-555.

142. QB Gao, H Zhao, X Ye, J He (2012) Prediction of pattern recognition receptor family using pseudo amino acid composition. Biochemical and Biophysical Research Communications 417: 73-77.

145. B Liao, Q Xiang, D Li (2012) Incorporating Secondary Features into the General form of Chou's PseAAC for Predicting Protein Structural Class. Protein \& Peptide Letters 19: 1133-1138.

146. WZ Lin, JA Fang, X Xiao, KC Chou (2012) Predicting Secretory Proteins of Malaria Parasite by Incorporating Sequence Evolution Information into Pseudo Amino Acid Composition via Grey System Model. PLoS One 7: e49040.

147. L Liu, XZ Hu, XX Liu, Y Wang, SB Li (2012) Predicting Protein Fold Types by the General Form of Chou's Pseudo Amino Acid Composition: Approached from Optimal Feature Extractions. Protein \& Peptide Letters 19: 439-449.

148. S Mei (2012) Multi-kernel transfer learning based on Chou's PseAAC formulation for protein submitochondria localization. Journal of Theoretical Biology 293: 121-130.

149. S Mei (2012) Predicting plant protein subcellular multi-localization by Chou's PseAAC formulation based multi-label homolog knowledge transfer learning. Journal of Theoretical Biology 310: 80-87.

150. L Nanni, S Brahnam, A Lumini (2012) Wavelet images and Chou's pseudo amino acid composition for protein classification. Amino Acids 43: 657-665.

151. L Nanni, A Lumini, D Gupta, A Gar (2012) Identifying bacterial virulent proteins by fusing a set of classifiers based on variants of Chou's pseudo amino acid composition and on evolutionary information. IEEE-ACM Transaction on Computational Biolology and Bioinformatics 9: 467-475.

152. XH Niu, XH Hu, F Shi, JB Xia (2012) Predicting Protein Solubility by the General Form of Chou's Pseudo Amino Acid Composition: Approached from Chaos Game Representation and Fractal Dimension. Protein \& Peptide Letters 19: 940-948.

153. YF Qin, CH Wang, XQ Yu, J Zhu, TG Liu, XQ Zheng (2012) Predicting Protein Structural Class by Incorporating Patterns of Over- Represented k-mers into the General form of Chou's PseAAC. Protein \& Peptide Letters 19: 388-397.

154. LY Ren, YS Zhang, I Gutman (2012) Predicting the Classification of Transcription Factors by Incorporating their Binding Site Properties into a Novel Mode of Chou's Pseudo Amino Acid Composition. Protein \& Peptide Letters 19: 1170-1176.

155. XY Sun, SP Shi, JD Qiu, SB Suo, SY Huang, RP Liang (2012) Identifying protein quaternary structural attributes by incorporating physicochemical properties into the general form of Chou's PseAAC via discrete 
wavelet transform. Molecular BioSystems 8: 3178-3184. 156. J Wang, Y Li, Q Wang, X You, J Man, C Wang, X Gao (2012) ProClusEnsem: predicting membrane protein types by fusing different modes of pseudo amino acid composition. Comput Biol Med 42: 564-574.

157. X Yu, X Zheng, T Liu, Y Dou, J Wang (2012) Predicting subcellular location of apoptosis proteins with pseudo amino acid composition: approach from amino acid substitution matrix and auto covariance transformation. Amino Acids 42: 1619-25.

158. XW Zhao, ZQ Ma, MH Yin (2012) Predicting protein-protein interactions by combing various sequence- derived features into the general form of Chou's Pseudo amino acid composition. Protein \& Peptide Letters 19: 492-500.

159. Zia-ur-Rehman, A Khan (2012) Identifying GPCRs and their Types with Chou's Pseudo Amino Acid Composition: An Approach from Multi-scale Energy Representation and Position Specific Scoring Matrix. Protein \& Peptide Letters 19: 890-903.

160. DS Cao, QS Xu, YZ Liang (2013) propy: a tool to generate various modes of Chou's PseAAC. Bioinformatics 29: 960-962.

161. TH Chang, LC Wu, TY Lee, SP Chen, HD Huang, JT Horng (2013) EuLoc: a web-server for accurately predict protein subcellular localization in eukaryotes by incorporating various features of sequence segments into the general form of Chou's PseAAC. Journal of Computer-Aided Molecular Design 27: 91-103.

162. YK Chen, KB Li (2013) Predicting membrane protein types by incorporating protein topology, domains, signal peptides, and physicochemical properties into the general form of Chou's pseudo amino acid composition. Journal of Theoretical Biology 318: 1-12.

163. G L Fan, Q Z Li, Y C Zuo (2013) Predicting acidic and alkaline enzymes by incorporating the average chemical shift and gene ontology informations into the general form of Chou's PseAAC. Pocess Biochemistry 48: 1048-1053.

164. GL Fan, QZ Li (2013) Discriminating biolu inescent proteins by incorporating average chemical shift and evolutionary information into the general form of Chou's pseudo amino acid composition. Journal of Theoretical Biology 334: 45-51.

165. M Khosravian, FK Faramarzi, MM Beigi, M Behbahani, H Mohabatkar (2013) Predicting Antibacterial Peptides by the Concept of Chou's Pseudo amino Acid Composition and Machine Learning Methods. Protein \& Peptide Letters 20: 180-186.

166. H Lin, C Ding, LF Yuan, W Chen, H Ding, et al. (2013) Predicting subchloroplast locations of proteins based on the general form of Chou's pseudo amino acid composition: Approached from optimal tripeptide composition. International Journal of Biomethmatics 6: 1350003.

167. H Lin, C Ding, LF Yuan, W Chen, H Ding, et al. (2013) Predicting subchloroplast locations of proteins based on the general form of Chou's pseudo amino acid composition: approached from optimal tripeptide composition. International Journal of Biomathematics 6: 1350003.

168. B Liu, X Wang, Q Zou, Q Dong, Q Chen (2013) Protein remote homology detection by combining Chou's pseudo amino acid composition and profilebased protein representation. Molecular Informatics 32:775-782.

169. H Mohabatkar, MM Beigi, K Abdolahi, S Mohsenzadeh (2013) Prediction of Allergenic Proteins by Means of the Concept of Chou's Pseudo Amino Acid Composition and a Machine Learning Approach. Medicinal Chemistry 9: 133-137.

170. E Pacharawongsakda, T Theeramunkong (2013) Predict Subcellular Locations of Singleplex and Multiplex Proteins by Semi-Supervised Learning and Dimension-Reducing General Mode of Chou's PseAAC. IEEE Transactions on Nanobioscience 12: 311-320.

171. YF Qin, L Zheng, J Huang (2013) Locating apoptosis proteins by incorporating the signal peptide cleavage sites into the general form of Chou's Pseudo amino acid composition. International Journal of Quantum Chemistry 113:1660-1667.

172. AN Sarangi, M Lohani, R Aggarwal (2013) Prediction of Essential Proteins in Prokaryotes by Incorporating Various Physico-chemical Features into the General form of Chou's Pseudo Amino Acid Composition. Protein Pept Lett 20: 781-795.

173. S Wan, MW Mak, SY Kung, Goasvm (2013) A subcellular location predictor by incorporating termfrequency gene ontology into the general form of Chou's pseudo amino acid composition. Journal of Theoretical Biology 323: 40-48.

174. X Wang, GZ Li, WC Lu, Virus-ECC-mPLoc (2013) a multi-label predictor for predicting the subcellular localization of virus proteins with both single and multiple sites based on a general form of Chou's pseudo amino acid composition. Protein \& Peptide Letters 20: 309-317.

175. X Xiao, JL Min, P Wang, KC Chou (2013) iCDIPseFpt: Identify the channel-drug interaction in cellular networking with PseAAC and molecular fingerprints. Journal of Theoretical Biology 337C: 71-79.

176. N Xiaohui, L Nana, X Jingbo, C Dingyan, P Yuehua, et al. (2013) Using the concept of Chou's pseudo amino acid composition to predict protein solubility: An approach with entropies in information theory. Journal of Theoretical Biology 332: 211-217.

177. HL Xie, L Fu, XD Nie (2013) Using ensemble SVM 
to identify human GPCRs N-linked glycosylation sites based on the general form of Chou's PseAAC. Protein Eng Des Sel 26: 735-742.

178. Y Xu, J Ding, LY Wu, KC Chou (2013) iSNOPseAAC: Predict cysteine S-nitrosylation sites in proteins by incorporating position specific amino acid propensity into pseudo amino acid composition PLoS ONE 8: e55844.

179. Y Xu, XJ Shao, LY Wu, NY Deng, KC Chou (2013) iSNO-AAPair: incorporating amino acid pairwise coupling into PseAAC for predicting cysteine S-nitrosylation sites in proteins. PeerJ 1: e171.

180. P Du, S Gu, Y Jiao (2014) PseAAC-General: Fast building various modes of general form of Chou's pseudo amino acid composition for large-scale protein datasets. International Journal of Molecular Sciences 15: 3495-3506.

181. Z Hajisharifi, M Piryaiee, M Mohammad Beigi, M Behbahani, H Mohabatkar (2014) Predicting anticancer peptides with Chou's pseudo amino acid composition and investigating their mutagenicity via Ames test. Journal of Theoretical Biology 341: 34-40.

182. GS Han, ZG Yu, V Anh (2014) A two-stage SVM method to predict membrane protein types by incorporating amino acid classifications and physicochemical properties into a general form of Chou's PseAAC. J Theor Biol 344: 31-39.

183. M Hayat, N Iqbal (2014) Discriminating protein structue classes by incorporating Pseudo Average Chemical Shift to Chou's general PseAAC and Support Vector Machine. Comput Methods Programs Biomed 116: 184-92.

184. C Jia, X Lin, Z Wang (2014) Prediction of Protein S-Nitrosylation Sites Based on Adapted Normal Distribution Bi-Profile Bayes and Chou's Pseudo Amino Acid Composition. Int J Mol Sci 15: 10410-23.

185. L Kong, L Zhang, J Lv (2014) Accurate prediction of protein structural classes by incorporating predicted secondary structure information into the general form of Chou's pseudo amino acid composition. J Theor Biol 344: 12-18.

186. L Li, S Yu, W Xiao, Y Li, M Li, et al. (2014) Prediction of bacterial protein subcellular localization by incorporating various features into Chou's PseAAC and a backward feature selection approach. Biochimie 104: 100-107.

187. B Liu, J Xu, X Lan, R Xu, J Zhou, et al. (2014) iDNA-Prot|dis: identifying DNA-binding proteins by incorporating amino acid distance-pairs and reduced alphabet profile into the general pseudo amino acid composition. PLoS ONE 9: e106691.

186. L Li, S Yu, W Xiao, Y Li, M Li, et al. (2014) Prediction of bacterial protein subcellular localization by incorporating various features into Chou's PseAAC and a backward feature selection approach. Biochimie 104: 100-107.

187. B Liu, J Xu, X Lan, R Xu, J Zhou, et al. (2014) iDNA-Prot|dis: identifying DNA-binding proteins by incorporating amino acid distance-pairs and reduced alphabet profile into the general pseudo amino acid composition. PLoS ONE 9: e106691.

189. L Nanni, S Brahnam, A Lumini (2014) Prediction of protein structure classes by incorporating different protein descriptors into general Chou's pseudo amino acid composition. J Theor Biol 360: 109-116.

190. WR Qiu, X Xiao, KC Chou (2014) iRSpotTNCPseAAC: Identify recombination spots with trinucleotide composition and pseudo amino acid components. Int J Mol Sci (IJMS) 15: 1746-1766.

191. WR Qiu, X Xiao, WZ Lin, KC Chou (2014) iMethylPseAAC: Identification of Protein Methylation Sites via a Pseudo Amino Acid Composition Approach. Biomed Res Int 947416.

192. Y Xu, X Wen, XJ Shao, NY Deng, KC Chou (2014) iHyd-PseAAC: Predicting hydroxyproline and hydroxylysine in proteins by incorporating dipeptide position-specific propensity into pseudo amino acid composition. International Journal of Molecular Sciences (IJMS) 15: 7594-7610.

193. Y Xu, X Wen, LS Wen, LY Wu, NY Deng, et al. (2014) iNitro-Tyr: Prediction of nitrotyrosine sites in proteins with general pseudo amino acid composition. Plos One 9: e105018.

194. J Zhang, P Sun, X Zhao, Z Ma (2014) PECM: Prediction of extracellular matrix proteins using the concept of Chou's pseudo amino acid composition. Journal of Theoretical Biology 363: 412-418.

195. J Zhang, X Zhao, P Sun, Z Ma (2014) PSNO: Predicting Cysteine S-Nitrosylation Sites by Incorporating Various Sequence-Derived Features into the General Form of Chou's PseAAC. Int J Mol Sci 15: 11204-19.

196. L Zhang, X Zhao, L Kong (2014) Predict protein structural class for low-similarity sequences by evolutionary difference information into the general form of Chou's pseudo amino acid composition. J Theor Biol 355: 105-110.

197. YC Zuo, Y Peng, L Liu, W Chen, L Yang, GL Fan $\mathrm{m}$ (2014) Predicting peroxidase subcellular location by hybridizing different descriptors of Chou's pseudo amino acid patterns. Anal Biochem 458: 14-19.

198. S. Ahmad, M. Kabir, M. Hayat, Identification of Heat Shock Protein families and J-protein types by incorporating Dipeptide Composition into Chou's general PseAAC. Comput Methods Programs Biomed 122 (2015) 165-74.

199. F Ali, M Hayat (2015) Classification of membrane protein types using Voting Feature Interval in 
combination with Chou's Pseudo Amino Acid Composition. J Theor Biol 384: 78-83.

200. L Chen, C Chu, T Huang, X Kong YD Cai (2015) Prediction and analysis of cell-penetrating peptides using pseudo amino acid composition and random forest models. Amino Acids doi:10.1007/s00726-0151974-5.

201. A Dehzangi, R Heffernan, A Sharma, J Lyons, K Paliwal A (2015) Sattar, Gram-positive and Gram-negative protein subcellular localization by incorporating evolutionary-based descriptors into Chou's general PseAAC. J Theor Biol 364: 284-294.

202. GL Fan, XY Zhang, YL Liu, Y Nang, H Wang (2015) DSPMP: Discriminating secretory proteins of malaria parasite by hybridizing different descriptors of Chou's pseudo amino acid patterns. J Comput Chem 36: 2317-2327.

203. C Huang, JQ Yuan (2015) Simultaneously Identify Three Different Attributes of Proteins by Fusing their Three Different Modes of Chou's Pseudo Amino Acid Compositions. Protein Pept Lett 22: 547-556.

204. J Jia, Z Liu, X Xiao, KC Chou (2015) iPPI-Esml: an ensemble classifier for identifying the interactions of proteins by incorporating their physicochemical properties and wavelet transforms into PseAAC. J Theor Biol 377: 47-56.

205. Z Ju, JZ Cao, H Gu (2015) iLM-2L: A two-level predictor for identifying protein lysine methylation sites and their methylation degrees by incorporating K-gap amino acid pairs into Chous general PseAAC. J Theor Biol 385: 50-57.

206. ZU Khan, M Hayat MA Khan (2015) Discrimination of acidic and alkaline enzyme using Chou's pseudo amino acid composition in conjunction with probabilistic neural network model. J Theor Biol 365:197-203.

207. R Kumar, A Srivastava, B Kumari, M Kumar (2015) Prediction of beta-lactamase and its class by Chou's pseudo amino acid composition and support vector machine. J Theor Biol 365: 96-103.

208. B Liu, J Chen, X Wang (2015) Protein remote homology detection by combining Chou's distancepair pseudo amino acid composition and principal component analysis. Mol Genet Genomics 290: 19191931 .

209. B Liu, J Xu, S Fan, R Xu, J Jiyun Zhou, et al. (2015) PseDNA-Pro: DNA-binding protein identification by combining Chou's PseAAC and physicochemical distance transformation. Molecular Informatics 34: 8-17

210. M Mandal, A Mukhopadhyay, U Maulik (2015) Prediction of protein subcellular localization by incorporating multiobjective PSO-based feature subset selection into the general form of Chou's PseAAC. Med
Biol Eng Comput 53: 331-344.

211. V Sanchez, AM Peinado, JL Perez-Cordoba, AM Gomez (2015) A new signal characterization and signal-based Chou's PseAAC representation of protein sequences. J Bioinform Comput Biol 13:1550024.

212. R Sharma, A Dehzangi, J Lyons, K Paliwal, T Tsunoda, A Sharma (2015) Predict Gram-Positive and Gram-Negative Subcellular Localization via Incorporating Evolutionary Information and Physicochemical Features Into Chou's General PseAAC. IEEE Trans Nanobioscience 14: 915-926.

213. X Wang, W Zhang, Q Zhang, GZ Li (2015) MultiPSChlo: multi-label protein subchloroplast localization prediction with Chou's pseudo amino acid composition and a novel multi-label classifier. Bioinformatics 31: 2639-2645.

214. R Xu, J Zhou, B Liu, YA He, Q Zou, et al. (2015) Identification of DNA-binding proteins by incorporating evolutionary information into pseudo amino acid composition via the top-n-gram approach. Journal of Biomolecular Structure \& Dynamics (JBSD) 33: $1720-1730$.

215. M Zhang, B Zhao, X Liu (2015) Predicting industrial polymer melt index via incorporating chaotic characters into Chou's general PseAAC. Chemometrics and Intelligent Laboratory Systems (CHEMOLAB) 146: 232-240.

216. SL Zhang (2015) Accurate prediction of protein structural classes by incorporating PSSS and PSSM into Chou's general PseAAC. Chemometrics and Intelligent Laboratory Systems (CHEMOLAB) 142: 28-35.

217. PP Zhu, WC Li, ZJ Zhong, EZ Deng, H Ding, et al. (2015) Predicting the subcellular localization of mycobacterial proteins by incorporating the optimal tripeptides into the general form of pseudo amino acid composition. Mol Biosyst 11: 558-63.

218. K Ahmad, M Waris, M Hayat (2016) Prediction of Protein Submitochondrial Locations by Incorporating Dipeptide Composition into Chou's General Pseudo Amino Acid Composition. J Membr Biol 249: 293-304. 219. M Behbahani, H Mohabatkar, M Nosrati (2016) Analysis and comparison of lignin peroxidases between fungi and bacteria using three different modes of Chou's general pseudo amino acid composition. J Theor Biol 411: $1-5$.

220. GL Fan, YL Liu, H Wang (2016) Identification of thermophilic proteins by incorporating evolutionary and acid dissociation information into Chou's general pseudo amino acid composition. J Theor Biol 407: 138142.

221. J Jia, Z Liu, X Xiao, B Liu, KC Chou (2016) Identification of protein-protein binding sites by incorporating the physicochemical properties and stationary wavelet transforms into pseudo amino acid 
composition (iPPBS-PseAAC). J Biomol Struct Dyn (JBSD) 34: 1946-1961.

222. J Jia, Z Liu, X Xiao, B Liu, KC Chou (2016) pSucLys: Predict lysine succinylation sites in proteins with PseAAC and ensemble random forest approach. Journal of Theoretical Biology 394: 223-230.

223. J Jia, Z Liu, X Xiao, B Liu, KC Chou (2016) iCarPseCp: identify carbonylation sites in proteins by Monto Carlo sampling and incorporating sequence coupled effects into general PseAAC. Oncotarget 7: 3455834570 .

224. J Jia, L Zhang, Z Liu, X Xiao, KC Chou (2016) pSumo-CD: Predicting sumoylation sites in proteins with covariance discriminant algorithm by incorporating sequence-coupled effects into general PseAAC. Bioinformatics 32: 3133-3141.

225. YS Jiao, PF Du (2016) Prediction of Golgi-resident protein types using general form of Chou's pseudo amino acid compositions: Approaches with minimal redundancy maximal relevance feature selection. J Theor Biol 402: 38-44.

226. Z Ju, JZ Cao, H Gu (2016) Predicting lysine phosphoglycerylation with fuzzy SVM by incorporating $\mathrm{k}$-spaced amino acid pairs into Chou's general PseAAC. J Theor Biol 397: 145-150.

227. M Kabir, M Hayat (2016) iRSpot-GAEnsC: identifing recombination spots via ensemble classifier and extending the concept of Chou's PseAAC to formulate DNA samples. Molecular Genetics and Genomics 291: 285-96.

228. WR Qiu, BQ Sun, X Xiao, ZC Xu, KC Chou (2016) iHyd-PseCp: Identify hydroxyproline and hydroxylysine in proteins by incorporating sequence-coupled effects into general PseAAC. Oncotarget 7: 44310-44321.

229. M Tahir, M Hayat (2016) iNuc-STNC: a sequencebased predictor for identification of nucleosome positioning in genomes by extending the concept of SAAC and Chou's PseAAC. Mol Biosyst 12: 2587-2593. 230. H Tang, W Chen H Lin (2016) Identification of immunoglobulins using Chou's pseudo amino acid composition with feature selection technique. Mol Biosyst 12: 1269-1275.

231. AK Tiwari (2016) Prediction of G-protein coupled receptors and their subfamilies by incorporating various sequence features into Chou's general PseAAC. Comput Methods Programs Biomed 134: 197-213.

232. C Xu, D Sun, S Liu, Y Zhang (2016) Protein Sequence Analysis by Incorporating Modified Chaos Game and Physicochemical Properties into Chou's General Pseudo Amino Acid Composition. J Theor Biol 406: 105-115.

233. HL Zou, X Xiao (2016) Predicting the Functional Types of Singleplex and Multiplex Eukaryotic Membrane Proteins via Different Models of Chou's Pseudo Amino
Acid Compositions. J Membr Biol 249: 23-29.

234. HL Zou, X Xiao (2016) Classifying Multifunctional Enzymes by Incorporating Three Different Models into Chou's General Pseudo Amino Acid Composition (doi:10.1007/s00232-016-9904-3). J Membr Biol 249: 561-567.

235. X Cheng, X Xiao, KC Chou (2017) pLoc-mPlant: predict subcellular localization of multi-location plant proteins via incorporating the optimal GO information into general PseAAC. Molecular BioSystems 13: 17221727.

236. X Cheng, X Xiao, KC Chou (2017) pLoc-mVirus: predict subcellular localization of multi-location virus proteins via incorporating the optimal GO information into general PseAAC. Gene 628: 315-321.

237. Z Ju, JJ He (2017) Prediction of lysine propionylation sites using biased SVM and incorporating four different sequence features into Chou's PseAAC. J Mol Graph Model 76: 356-363.

238. Z Ju, JJ He (2017) Prediction of lysine crotonylation sites by incorporating the composition of $\mathrm{k}$-spaced amino acid pairs into Chou's general PseAAC. J Mol Graph Model 77: 200-204.

239. M Khan, M Hayat, SA Khan, N Iqbal (2017) UnbDPC: Identify mycobacterial membrane protein types by incorporating un-biased dipeptide composition into Chou's general PseAAC. J Theor Biol 415: 13-19.

240. Y Liang, S Zhang (2017) Predict protein structural class by incorporating two different modes of evolutionary information into Chou's general pseudo amino acid composition. J Mol Graph Model 78: 110117.

241. LM Liu, Y Xu, KC Chou (2017) iPGK-PseAAC: identify lysine phosphoglycerylation sites in proteins by incorporating four different tiers of amino acid pairwise coupling information into the general PseAAC. Med Chem 13: 552-559.

242. PK Meher, TK Sahu, V Saini, AR Rao (2017) Predicting antimicrobial peptides with improved accuracy by incorporating the compositional, physicochemical and structural features into Chou's general PseAAC. Sci Rep 7: 42362.

243. WR Qiu, BQ Sun, X Xiao, D Xu, KC Chou (2017) iPhos-PseEvo: Identifying human phosphorylated proteins by incorporating evolutionary information into general PseAAC via grey system theory. Molecular Informatics 36 UNSP 1600010.

244. WR Qiu, QS Zheng, BQ Sun, X Xiao (2017) MultiiPPseEvo: A Multi-label Classifier for Identifying Human Phosphorylated Proteins by Incorporating Evolutionary Information into Chou's General PseAAC via Grey System Theory. Mol Inform 36 UNSP 1600085. 245. M Rahimi, MR Bakhtiarizadeh, A MohammadiSangcheshmeh, Oogenesis (2017) A sequence-based 
method for predicting oogenesis proteins by six different modes of Chou's pseudo amino acid composition. J Theor Biol 414: 128-136.

246. P Tripathi, PN Pandey (2017) A novel alignmentfree method to classify protein folding types by combining spectral graph clustering with Chou's pseudo amino acid composition. J Theor Biol 424: 49-54.

247. XXiao, X Cheng, SSu, Q Nao, KCChou (2017) pLocmGpos: Incorporate key gene ontology information into general PseAAC for predicting subcellular localization of Gram-positive bacterial proteins. Natural Science 9: 331-349.

248. C Xu, L Ge, Y Zhang, M Dehmer, I Gutman (2017) Prediction of therapeutic peptides by incorporating q-Wiener index into Chou's general PseAAC. J Biomed Inform doi:10.1016/j.jbi.2017.09.011.

249. Y Xu, C Li, KC Chou (2017) iPreny-PseAAC: identify C-terminal cysteine prenylation sites in proteins by incorporating two tiers of sequence couplings into PseAAC. Med Chem 13: 544-551.

250. B Yu, S Li, WY Qiu, C Chen, RX Chen, L Wang, MH Wang, Y Zhang (2017) Accurate prediction of subcellular location of apoptosis proteins combining Chou's PseAAC and PsePSSM based on wavelet denoising. Oncotarget 8: 107640-107665.

251. B Yu, L Lou, S Li, Y Zhang, W Qiu, X Wu, M Wang, B Tian (2017) Prediction of protein structural class for low-similarity sequences using Chou's pseudo amino acid composition and wavelet denoising. J Mol Graph Model 76: 260-273.

252. J Ahmad, M Hayat (2018) MFSC: Multi-voting based Feature Selection for Classification of Golgi Proteins by Adopting the General form of Chou's PseAAC components. J Theor Biol 463: 99-109.

253. S Akbar, M Hayat (2018) iMethyl-STTNC: Identification of $\mathrm{N}(6)$-methyladenosine sites by extending the Idea of SAAC into Chou's PseAAC to formulate RNA sequences. J Theor Biol 455: 205-211.

254. M Arif, M Hayat, Z Jan (2018) iMem-2LSAAC: A two-level model for discrimination of membrane proteins and their types by extending the notion of SAAC into Chou's pseudo amino acid composition. J Theor Biol 442: 11-21.

255. AH Butt, N Rasool, YD Khan (2018) Predicting membrane proteins and their types by extracting various sequence features into Chou's general PseAAC. Mol Biol Rep doi:10.1007/s11033-018-4391-5 .

256. X Cheng, X Xiao, KC Chou (2018) pLoc-mEuk: Predict subcellular localization of multi-label eukaryotic proteins by extracting the key GO information into general PseAAC. Genomics 110: 50-58.

257. X Cheng, X Xiao, KC Chou (2018) pLoc-mGneg: Predict subcellular localization of Gram-negative bacterial proteins by deep gene ontology learning via general PseAAC. Genomics 110: 231-239.

258. X Cheng, X Xiao, KC Chou (2018) pLoc-mHum: predict subcellular localization of multi-location human proteins via general PseAAC to winnow out the crucial GO information. Bioinformatics 34: 1448-1456.

259. X Cheng, X Xiao, KC Chou (2018) pLoc_balmGneg: predict subcellular localization of Gramnegative bacterial proteins by quasi-balancing training dataset and general PseAAC. Journal of Theoretical Biology 458: 92-102.

260. X Cheng, X Xiao, KC Chou (2018) pLoc_balmPlant: predict subcellular localization of plant proteins by general PseAAC and balancing training dataset Curr Pharm Des 24: 4013-4022.

261. E Contreras-Torres (2018) Predicting structural classes of proteins by incorporating their global and local physicochemical and conformational properties into general Chou's PseAAC. J Theor Biol 454: 139-145. 262. X Fu, W Zhu, B Liso, L Cai, L Peng, J Yang (2018) Improved DNA-binding protein identification by incorporating evolutionary information into the Chou's PseAAC. IEEE Access 20, https://doi.org/10.1109/ ACCESS 2876656.

263. AW Ghauri, YD Khan, N Rasool, SA Khan, KC Chou (2018) pNitro-Tyr-PseAAC: Predict nitrotyrosine sites in proteins by incorporating five features into Chou's general PseAAC. Curr Pharm Des 24: 40344043 .

264. F Javed, M Hayat (2018) Predicting subcellular localizations of multi-label proteins by incorporating the sequence features into Chou's PseAAC. Genomics https://doi.org/10.1016/j.ygeno.2018.09.004.

265. Z Ju, SY Wang (2018) Prediction of citrullination sites by incorporating $\mathrm{k}$-spaced amino acid pairs into Chou's general pseudo amino acid composition. Gene $664: 78-83$.

266. YD Khan, N Rasool, W Hussain, SA Khan, KC Chou (2018) iPhosT-PseAAC: Identify phosphothreonine sites by incorporating sequence statistical moments into PseAAC. Analytical Biochemistry 550: 109-116.

267. YD Khan, N Rasool, W Hussain, SA Khan, KC Chou (2018) iPhosY-PseAAC: identify phosphotyrosine sites by incorporating sequence statistical moments into PseAAC. Mol Biol Rep 45: 2501-2509.

268. MS Krishnan (2018) Using Chou's general PseAAC to analyze the evolutionary relationship of receptor associated proteins (RAP) with various folding patterns of protein domains. J Theor Biol 445: 62-74.

269. Y Liang, S Zhang (2018) Identify Gram-negative bacterial secreted protein types by incorporating different modes of PSSM into Chou's general PseAAC via Kullback-Leibler divergence. J Theor Biol 454: 2229. 
270. J Mei, Y Fu, J Zhao (2018) Analysis and prediction of ion channel inhibitors by using feature selection and Chou's general pseudo amino acid composition. J Theor Biol 456: 41-48.

271. J Mei, J Zhao (2018) Prediction of HIV-1 and HIV-2 proteins by using Chou's pseudo amino acid compositions and different classifiers. Sci Rep 8: 2359.

270. J Mei, Y Fu, J Zhao (2018) Analysis and prediction of ion channel inhibitors by using feature selection and Chou's general pseudo amino acid composition. J Theor Biol 456: 41-48.

271. J Mei, J Zhao (2018) Prediction of HIV-1 and HIV-2 proteins by using Chou's pseudo amino acid compositions and different classifiers. Sci Rep 8: 2359.

272. J Mei, J Zhao (2018) Analysis and prediction of presynaptic and postsynaptic neurotoxins by Chou's general pseudo amino acid composition and motif features. J Theor Biol 427: 147-153.

273. M Mousavizadegan, H Mohabatkar (2018) Computational prediction of antifungal peptides via Chou's PseAAC and SVM. J Bioinform Comput Biol 1850016.

274. SM Rahman, S Shatabda, S Saha, M Kaykobad, M Sohel Rahman (2018) DPP-PseAAC: A DNA-binding Protein Prediction model using Chou's general PseAAC. J Theor Biol 452: 22-34.

275. ES Sankari, DD Manimegalai (2018) Predicting membrane protein types by incorporating a novel feature set into Chou's general PseAAC. J Theor Biol 455: 319-328.

276. A Srivastava, R Kumar, M Kumar (2018) BlaPred: predicting and classifying beta-lactamase using a 3-tier prediction system via Chou's general PseAAC. J Theor Biol 457: 29-36.

277. S Zhang, X Duan (2018) Prediction of protein subcellular localization with oversampling approach and Chou's general PseAAC. J Theor Biol 437: 239-250. 278. S Zhang, Y Liang (2018) Predicting apoptosis protein subcellular localization by integrating autocross correlation and PSSM into Chou's PseAAC. J Theor Biol 457: 163-169.

279. S Adilina, DM Farid, S Shatabda (2019) Effective DNA binding protein prediction by using key features via Chou's general PseAAC. J Theor Biol 460: 64-78.

280. J Ahmad, M Hayat (2019) MFSC: Multi-voting based feature selection for classification of Golgi proteins by adopting the general form of Chou's PseAAC components. J Theor Biol 463: 99-109.

281. M Awais, W Hussain, YD Khan, N Rasool, SA Khan, KC Chou (2019) iPhosH-PseAAC: Identify phosphohistidine sites in proteins by blending statistical moments and position relative features according to the Chou's 5-step rule and general pseudo amino acid composition. IEEE/ACM Trans Comput Biol Bioinform
https://doi.org/10.1109/TCBB.2019.2919025 or https:// www.ncbi.nlm.nih.gov/pubmed/31144645 (2019).

282. M Behbahani, M Nosrati, M Moradi, H Mohabatkar (2019) Using Chou's General Pseudo Amino Acid Composition to Classify Laccases from Bacterial and Fungal Sources via Chou's Five-Step Rule. Applied Biochemistry and Biotechnology doi:10.1007/s12010019-03141-8 (2019).

283. AH Butt, N Rasool, YD Khan (2019) Prediction of antioxidant proteins by incorporating statistical moments based features into Chou's PseAAC. Journal of Theoretical Biology 473: 1-8.

284. G Chen, M Cao, J Yu, X Guo, S Shi (2019) Prediction and functional analysis of prokaryote lysine acetylation site by incorporating six types of features into Chou's general PseAAC. J Theor Biol 461: 92-101.

285. KC Chou (2019) An insightful 20-year recollection since the birth of pseudo amino acid components. Computers in Biology and Medicine in press (2019).

286. KC Chou (2019) Proposing pseudo amino acid components is an important milestone for proteome and genome analyses. International Journal for Peptide Research and Therapeutics (IJPRT) https:// doi.org/10.1007/s10989-019-09910-7 or https://link. springer.com/article/10.1007\%2Fs 10989-019-09910-7 (2019).

287. F Javed, M Hayat (2019) Predicting subcellular localization of multi-label proteins by incorporating the sequence features into Chou's PseAAC. Genomics 111: 1325-1332.

288. SJ Malebary, MSU Rehman, YD Khan (2019) iCrotoK-PseAAC: Identify lysine crotonylation sites by blending position relative statistical features according to the Chou's 5-step rule. PLoS One 14: e0223993.

289. Q Ning, Z Ma, X Zhao (2019) dForml(KNN)PseAAC: Detecting formylation sites from protein sequences using K-nearest neighbor algorithm via Chou's 5-step rule and pseudo components. J Theor Biol 470: 43-49.

290. M Nosrati, H Mohabatkar, M Behbahani (2019) Introducing of an integrated artificial neural network and Chou's pseudo amino acid composition approach for computational epitope-mapping of Crimean-Congo haemorrhagic fever virus antigens. International Immunopharmacology https://doi.org/10.1016/j. intimp.2019.106020 or https://www.sciencedirect.com/ science/article/pii/S1567576919321277 (2019).

291. Y Shen, J Tang, F Guo (2019) Identification of protein subcellular localization via integrating evolutionary and physicochemical information into Chou's general PseAAC. J Theor Biol 462: 230-239.

292. M Tahir, M Hayat, SA Khan (2019) iNuc-extPseTNC: an efficient ensemble model for identification of nucleosome positioning by extending the concept 
of Chou's PseAAC to pseudo-tri-nucleotide composition. Mol Genet Genomics 294: 199-210.

293. L Wang, R Zhang, Y Mu (2019) Fu-SulfPred: Identification of Protein S-sulfenylation Sites by Fusing Forests via Chou's General PseAAC. J Theor Biol 461: 51-58.

294. X Xiao, X Cheng, G Chen, Q Mao, KC Chou (2019) pLoc_bal-mVirus: Predict Subcellular Localization of Multi-Label Virus Proteins by Chou's General PseAAC and IHTS Treatment to Balance Training Dataset. Med Chem 15: 496-509.

295. YD Khan, N Amin, W Hussain, N Rasool, SA Khan, KC Chou (2020) iProtease-PseAAC(2L): A twolayer predictor for identifying proteases and their types using Chou's 5-step-rule and general PseAAC. Anal Biochem 588: 113477.

296. KC Chou (2019) Two kinds of metrics for computational biology. Genomics https:// www.sciencedirect.com/science/article/pii/ S0888754319304604? via\%3Dihub (2019).

297. KC Chou (2019) An insightful recollection for predicting protein subcellular locations in multilabel systems. Genomics http://doi.org/10.1016/j. ygeno.2019.08.008 or https://www.sciencedirect.com/ science/article/pii/S0888754319304604?via\%3Dihub (2019).

298. KC Chou (2019) Progresses in predicting posttranslational modification. International Journal of Peptide Research and Therapeutics (IJPRT) https:/ doi.org/10.1007/s10989-019-09893-5 or https://link. springer.com/article/10.1007\%2Fs10989-019-09893-5 (2019).

299. KC Chou (2019) Recent Progresses in Predicting Protein Subcellular Localization with Artificial Intelligence (AI) Tools Developed Via the 5-Steps Rule. Japanese Journal of Gastroenterology and Hepatology https:/doi.org/www.jjgastrohepto.org or https://www. jjgastrohepto.org/ (2019).

300. KC Chou (2019) An insightful recollection since the distorted key theory was born about 23 years ago. Genomics https://doi.org/10.1016/j.ygeno.2019.09.001 or https://www.sciencedirect.com/science/article/pii/ S0888754319305543?via\%3Dihub (2019).

301. KC Chou (2019) Artificial intelligence (AI) tools constructed via the 5-steps rule for predicting post-translational modifications. Trends in Artificial Inttelengence (TIA) 3: 60-74.

302. KC Chou (2020) Distorted Key Theory and Its Implication for Drug Development. Current Genomics http://www.eurekaselect.com/175823/article or http:// www.eurekaselect.com/175823/article (2020).

303. KC Chou (2019) An insightful recollection since the birth of Gordon Life Science Institute about 17 years ago. Advancement in Scientific and Engineering Research 4: 31-36.
304. KC Chou (2019) Gordon Life Science Institute: Its philosophy, achievements, and perspective. Annals of Cancer Therapy and Pharmacology 2: 1-26.
Copyright: (02019 Kuo-Chen Chou. This is an open-access article distributed under the terms of the Creative Commons Attribution License, which permits unrestricted use, distribution, and reproduction in any medium, provided the original author and source are credited. 